\title{
Perceptions of the Use of the Diode Laser in Dental Surgery: A Qualitative Study
}

\author{
Kamila Gomes Soares ${ }^{1}$, Tallyta Yohana Andrade de Carvalho' ${ }^{\circledR}$, Alice Machado Carvalho Santos ${ }^{1}$, \\ Lívio Barros Silveira ${ }^{\circledR} \mathbb{D}$, Lidiane Cristina Machado Costa ${ }^{3}$, Maria Luiza da Matta Felisberto \\ Fernandes ${ }^{1}\left(\mathbb{D}\right.$, Alexandre Moreira Fernandes ${ }^{1}(\mathbb{D}$
}

\begin{abstract}
${ }^{1}$ Department of Pediatric Dentistry, Faculty of Dentistry, Newton Paiva University Center, Belo Horizonte, MG, Brazil. ${ }^{2}$ Department of Periodontology and Laser, Faculty of Dentistry, Arnaldo Faculty, Belo Horizonte, MG, Brazil.

${ }^{3}$ Department of Periodontology, Faculty of Dentistry, Newton Paiva University Center, Belo Horizonte, MG, Brazil.
\end{abstract}

Author to whom correspondence should be addressed: Maria Luiza M. F. Fernandes, Department of Pediatric Dentistry, Faculty of Dentistry, Newton Paiva University Center, Belo Horizonte, MG, Brazil. Phone: +5531 99976-1406. E-mail: marialuizadamatta@gmail.com.

Academic Editors: Alessandro Leite Cavalcanti and Wilton Wilney Nascimento Padilha

Received: 25 July 2019 / Accepted: 17 April 2020 / Published: 15 May 2020

How to cite this article: Soares KG, Carvalho TYA, Santos AMC, Silveira LB, Costa LCM, Fernandes MLMF. Perceptions of the use of the diode laser in dental surgery: a qualitative study. Pesqui Bras Odontopediatria Clín Integr. 2020; 20:e5039. https://doi.org/10.1590/pboci.2020.083

\begin{abstract}
Objective: To discover the perceptions of pediatric patients, their parents and undergraduate Dentistry students of the use of the diode laser in frenectomy surgeries. Material and Methods: A qualitative study was conducted through semi-structured interviews, recorded and transcribed with subsequent content analysis. Twelve healthy children (5-8 years old) who needed a frenectomy were selected and invited, together with their parents, to undergo laser diode surgery. In addition, 28 undergraduate dentistry students were invited to attend the procedures. One week after performing the surgical procedures, the children (Group 1), their parents (Group 2) and the students who attended the procedures (Group 3) were individually interviewed for the thematic analysis. Results: The analysis of the conversations identified three emerging contents: positive thoughts on the use of diode laser; frustrations from the use of diode laser; and aspects related to professional training. Conclusion: The results pointed to the acceptance of surgical laser use in pediatric dentistry; however, the feelings of frustration indicate that its use requires guidance from the child and his/her parents, in addition to careful handling and specific training.
\end{abstract}

Keywords: Pediatric Dentistry; Oral Surgical Procedures; Lingual Frenum; Labial Frenum; Laser Therapy. 


\section{Introduction}

The $808 \mathrm{~nm}$ diode laser is a type of laser that is indicated for soft tissue surgeries in the oral cavity [1]. This type of laser consists of a semiconductor crystal that uses solid state elements to transform electrical energy into light energy. This light energy is well absorbed by the soft tissues due to the approximation of the wavelength generated by the laser with melanin, hemoglobin and collagen as absorption coefficients [2].

Several studies have demonstrated the advantages of this type of laser, which include better hemostasis and healing, no need for suture and trans and postoperative comfort [3]. The 810 nm diode laser has proven to be a reliable resource in the therapy of benign oral soft tissue lesions, because they achieve acceptable wound healing with minimal adverse effects [4].

Some of the procedures performed with the diode laser include granulation tissue removal; excisional and incisional biopsies of benign and malignant lesions; irradiation of aphthous ulcers; coagulation of free gingival graft donor sites; gingival depigmentation; gingivoplasty; gingivectomy; and frenectomy [5]. Despite the reports on the advantages, to the best of our knowledge and literary research we did not find qualitative studies on the use of surgical lasers. The objective of this qualitative study was to conduct an analysis to discover the perceptions of children, their parents and undergraduate dentistry students of the use of a diode laser in lip and lingual frenectomy surgeries performed at a university dental clinic.

\section{Material and Methods}

\section{Study Design}

This study has a qualitative approach by sampling for convenience. The eligibility criteria for participation in the study were as follows: children between the ages of 5 to 10 years who were patients at the Dental Dchool, Newton Paiva University Center; children whose parents reported that their children did not have systemic or mental disorders; children who were not under medical treatment or using drugs; and children who required a frenectomy due to the clinical characteristics of short lingual frenulum, a hypertrophic frenulum associated with an upper anterior diastema and low insertion in the gingival margin.

The participants were divided into three groups: Group 1: children who needed to have a labial and lingual frenectomy; Group 2: children's parents; and Group 3: 28 undergraduate dental students. In addition, all undergraduate dentistry students who were responsible for the clinical dental care of eligible children and who agreed to participate in the research were also invited to attend the procedures. These students were from the seventh term of the dentistry course and thus all had already had experience in dental care for children during the previous semester. To perform the surgeries, the patients were treated at a laser therapy extension clinic at the university from April to October 2018.

\section{Description of the Surgical Technique}

Benzocaine 20\% (topical anesthetic Benzotop 20\% 12 g - DFL Indústria e Comércio S.A., Rio de Janeiro, RJ, Brazil) was used as a topical anesthetic and was applied with a cotton swab after drying the mucous. An infiltrative anesthesia with anesthetic lidocaine 2\% with Epinephrine (Alphacaine 2\% 1:100.000 DFL Indústria e Comércio S.A., Rio de Janeiro, RJ, Brazil) in a dental carpule syringe was used.

The diode laser (Brand MMO and model - TW Surgical, MM Optics, São Carlos, SP, Brazil) was programmed with the following protocol: Wavelength $-808 \mathrm{~nm}$; Contact mode $-600 \mu \mathrm{m}$ fiber used; Power: $2000 \mathrm{~mW}$ - Pulsed; Frequency: 20 Hertz; Pulse duration: 76\% - 38,0 ms. With these parameters we report that the Power Density (Intensity) was $714 \mathrm{~W} / \mathrm{cm}^{2}$, the Energy Density (Fluency/dose) was $27 \mathrm{~J} / \mathrm{cm}^{2} \mathrm{deposited}$ 
per pulse and we can conclude that $542 \mathrm{~J} / \mathrm{cm}^{2}$ were deposited in 1 second of action. After programming, the fiber tip was activated on carbon paper. Then the procedure was initiated by the contact of brushing the fiber above the insertion of the frenulum. At the end of surgery there was no need for suture and hemostasis.

All surgical procedures using the diode laser technique were performed by a single professor (LBS) with experience, training and knowledge in the area. The treatments were upper lip frenectomies and lingual frenectomies. The use of the same analgesic (Paracetamol $200 \mathrm{mg} / \mathrm{mL}, 15 \mathrm{mg} / \mathrm{Kg} /$ dose, every 6 hours) was recommended in case of postoperative discomfort.

\section{Interviews}

One week after performing the surgical procedures, the children (Group 1), their parents (Group 2) and the students who attended the procedures (Group 3) were individually interviewed in a reserved room.

All studies of the interviews were conducted in the Department of Pediatric Dentistry of NPUC. To ensure equitable results for all participants, all interviews were conducted by the same professional with experience in qualitative research (MLMFF). In this study, face-to-face interviews were used, in conjunction with recorded, semi-structured interviews [6]

The interviews were semi-structured with an interview script to discover the opinion about the experiences with the surgical procedures (Frame 1). The data analysis included an analysis of the recordings of the semi-structured interviews. All participants agreed to record the interview. All data collected from the interviews were transcribed in full, and a thematic analysis was performed using the QSR NVivo 11 Qualitative Data Analysis Software (QSR International Pty Ltd, Victoria, AU). Thematic analysis included the coding of raw data and central categories under themes used to build thematic axes and interpret new meanings $[6,7]$. This method allows researchers to gain a deeper understanding of patients' feelings about the procedure.

We also collected some individual characteristics of the participants in the research, such as gender, age, term of study in dentistry, average family income and degree of relationship with the children submitted to the surgeries. The interviews had an average duration of 15 minutes. Later, they were recorded and transcribed.

\section{Frame 1. Interview script.}

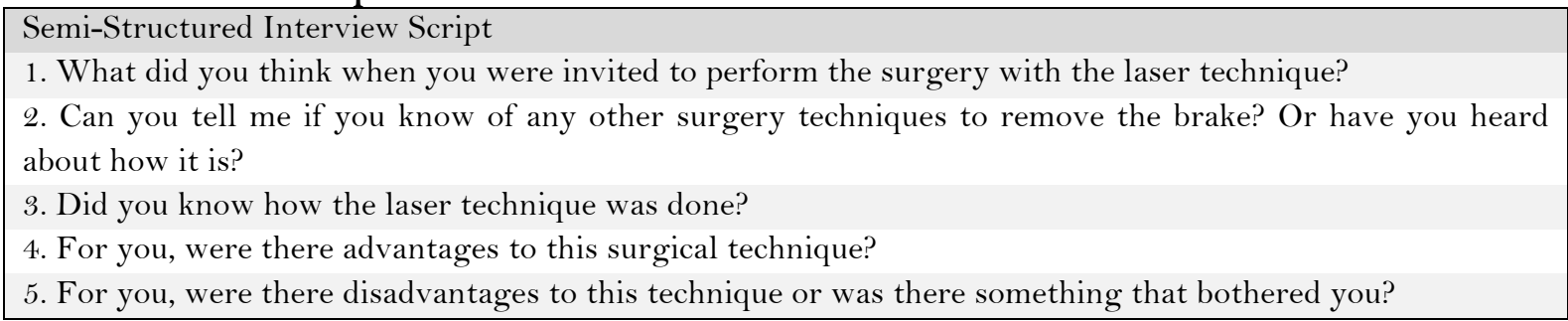

Ethical Aspects

This research was approved by the Ethics Committee of the Newton Paiva University Center (CAAE 88127418.5.0000.5097). All participants signed the consent form for research.

\section{Results}

Only two pairs of children and their parents did not consent to participate in the research for personal reasons. The individual characteristics of the research participants are described in Table 1 . The average family 
income of the patients was two Brazilian minimum wage salaries (BMW), which corresponds to US $\$ 471.00$ monthly.

Table 1. Individual characteristics of the participants.

\begin{tabular}{lccc}
\hline \multicolumn{1}{c}{ Variables } & G1 & Groups & G3 \\
\hline Number of Participants & 12 & G2 & 28 \\
Gender & 6 females and 6 males & 10 mothers and 2 fathers & 27 females and 1 males \\
Age & $5-8$ years old & NA* & $19-42$ years old \\
Average Family Income & US $\$ 471.00$ & US $\$ 471.00$ & NA* \\
Relationship with the Child & NA* & 10 mothers and 2 fathers & NA* \\
Period in the Dentistry Course & NA* & NA* & From 7th to 9th term \\
\hline
\end{tabular}

*Not Applicable.

\section{Overall Experience}

The interviews consisted of questions in two primary parts: (1) the thoughts regarding their overall surgical technique and (2) the reactions about this type of the procedure.

Two important findings of the patients' overall experience were derived during the interviews. First, $83.3 \%$ ( 10 of 12 ) of children and $91.6 \%$ ( 11 of 12 ) of parents were pleased with the surgical treatment. They stated that the procedure was quick, painless and didn't have bleeding. In addition, 91.6\% (11 of 12$)$ of undergraduate dental students expressed positive feelings about the procedure. The positive observations found the technique of the procedure to be considered simple for the visualization of the surgical field, had a quick surgical time and quick recovery time. In addition, participants demonstrated confidence with the technique used, pain control, the minimal trans and postoperative discomfort, rapid healing, absence of bleeding and no need for suture. These findings are seen in the statements below:

\footnotetext{
"My feelings are positive because the procedure is precise, the healing is easier and there is not much bleeding; it does not expose as much as conventional surgery that opens and cuts ..." (Father)

"I think this technique has more advantages than disadvantages because, besides not having bleeding, healing is faster, surgery itself is faster..." (Undergraduate student, 8th term)
}

Second, 91.6\% (11 of 12) of patients and their parents expressed that they received very little or no information regarding the procedure prior to the procedure. Only one father also indicated that he was misinformed by other people who had undergone a similar procedure, and therefore he felt unnecessarily stressed.

"I talked to a friend whose daughter had undergone such treatment. She told me that the procedure was terrifying because smoke came out of her daughter's mouth. So I was very apprehensive. But it wasn't as bad as the stories". (Father)

The aspects related to the professional formation of the students of Dentistry showed the aggregation of professional knowledge as a positive point for the undergraduate course. The interviews revealed little knowledge of the technique using the diode laser and little discussion of this technique during the course. However, a preference for conducting surgery using the diode laser compared to the conventional scalpel technique was observed. These aspects are demonstrated in the following statements:

"I found it very interesting because it is a technique that is not discussed much in college." (Undergraduate student, 9th term)

"... first, I liked it, I found the way it is done to be very interesting, it added a lot to my undergraduate knowledge." (Undergraduate student, 7 th term) 
Experience During Different Stages of the Procedure

The results suggest that, during each stage of the procedure, the participants experienced several problems that also influenced their overall experience. It was found that the equipment used had the greatest impact on the group of undergraduate students. The emerging frustrations pointed out a need for specific knowledge and training for the handling of equipment and a long surgical time.

"I thought laser surgery was faster. In addition, specific training is required to handle surgical equipment. For me, from a dental point of view, this is not as simple as I thought." (Undergraduate student, 8 th term)

An unpleasant (ugly) clinical aspect of the surgical wound and a strong smell during surgery were perceptions and complaints from some children and parents. In addition, parents and students participating in the study considered tissue ablation, the need for infiltrative anesthesia and the adaptation of children's behavior as factors that made the technique difficult. Some examples of statements that cite frustrations are:

"My gums are still very ugly..." (Young patient, 6 years old)

"I was afraid that the smell and smoke would disturb my daughter, that is, she would be frightened..." (Mother)

"Even I was afraid of that barbecue-smelling smoke that was happening in the girl's mouth. I was waiting for the time when she would no longer cooperate with the surgery." (Undergraduate student, 7 th term)

A thematic analysis resulted in two central categories used for the construction of thematic axes and the interpretation of the meanings of the interviews (Figure 1).

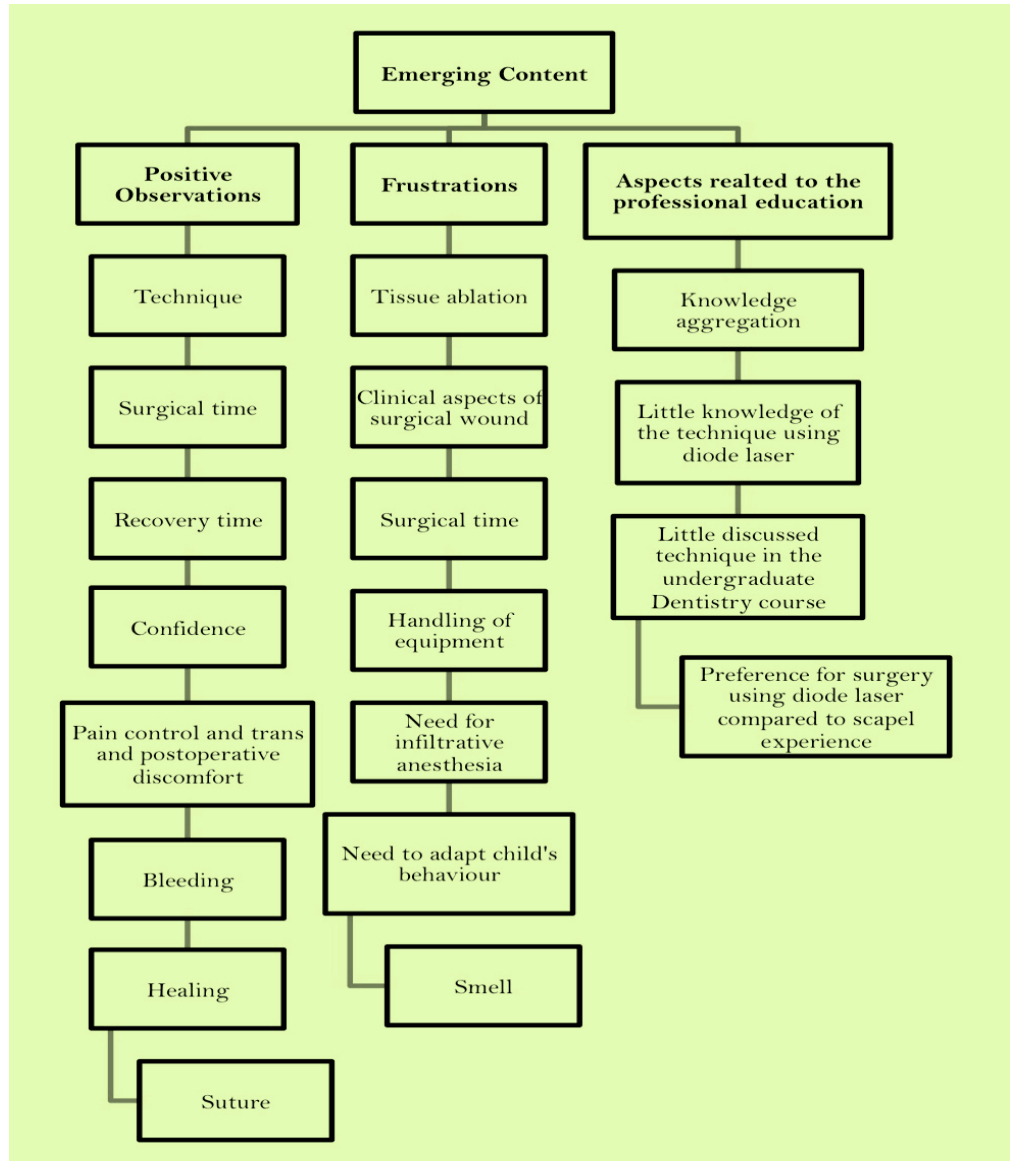

Figure 1. Outline of emerging content. 


\section{Discussion}

In this study, $100 \%$ of the participants in the three research groups were motivated to participate in the research and to know about the laser surgical procedure. However, $91.6 \%$ of participants reported that they were misinformed about the procedure which, according to the interviews, caused stress for one of the research participants. This lack of knowledge and information also creates frustrations or anxiety.

The positive observations were technique; surgical time; recovery time; confidence; pain control and trans and postoperative discomfort; bleeding; healing; and suturing. Our findings are consistent with the findings in adults [8]. Two clinical cases in which the laser diode was used to remove pyogenic granuloma were in a 53-year-old woman and gingival depigmentation in a 26-year-old patient. From a professional standpoint, the authors concluded that this technique was easy to apply, had better coagulation, had no need for sutures and had less swelling and postoperative pain [8]. However, the comparison with our results should be done with caution, as they represent different stages of life and clinical indications. In addition, consideration that the professional point of view in our study was given by students still in the undergraduate course and both samples of the study were samples of convenience should be taken into account.

The high intensity diode laser can be used as an alternative technique for pediatric patients because it requires less surgical time and a more comfortable postoperative period [9]. In the present study there was no complaint about the time by the children, but the reports of the students interviewed demonstrated the need for care with the handling and adaptation of the child's behavior.

The preference for the use of a laser for surgeries, according to the reports of the three groups, is supported by positive perceptions about not needing suture, less inflammation and pain, shorter treatment time, better repair, good recovery and rare intra and postoperative complications. The characteristics of less postoperative discomfort, reduced bleeding and better gingival healing were also pointed out in the literature when the use of laser was compared to the conventional cold blade technique [10,11].

During the operation and completion of the incision, some emanations are released from the vaporization of the epithelium and produce a burning smell, which can cause stress and harm the patient [8]. According to the literature, our study found similar results.

In the present study, undergraduate dentistry students pointed out a need for specific knowledge and training to handle the equipment as a frustration. In fact, the need to understand the physical characteristics of the laser and the need to correctly train the team to observe the safety rules are addressed as a critical point for the use of a surgical laser [12]. No technology is used without proper training. In this way, this type of frustration can be easily remedied with professional training of technical and scientific excellence.

As for the emission of the light of the laser, several active media can be used. Regarding the need for anesthesia in the operative field, the use of the diode laser was compared with the Er: YAG laser [13]. The authors reported the need for local anesthesia in all patients submitted to surgery using the diode laser, unlike the Er:YAG laser, in which the majority of patients operated on by this laser did not have to undergo local anesthesia [13]. The anesthetic technique was not dispensed in the present study by the use of the diode laser. This justified the interviewees' perception of the need for anesthesia in all patients.

Considering the category related to the aspects of professional training, knowledge aggregation was a positive aspect found; the use of laser technology in child dental clinics is a topic that is still little explored in the scientific literature.

The present study has the limitation of not being able to extrapolate the results for the entire pediatric population and their relatives, as well as to all undergraduate students in Dentistry. The limitation of 
qualitative research is that the small sample size sometimes renders the results unreliable and not generalizable [14]. However, qualitative research has some advantages. Advantages that can be highlighted are the production of a detailed description and testimonials of feelings, opinions and experiences [14]. In this manner, this study provides a starting point for recent discussions about the use of this surgical technique in undergraduate studies. It is suggested that other studies with quantitative methodology and with representative samples be performed for broader knowledge of the themes that emerge here.

\section{Conclusion}

The results indicate the acceptance of the use of a laser in the pediatric dental clinic for surgical cases of labial and lingual frenectomy. However, the patient's discomfort and the need for instructions for children, parents and students point to the need to observe the following topics: The stress of the patient and their parents before surgery can be reduced by providing detailed information about the procedure and the laser equipment to be used; The items used during the procedure must reduce the technical effort and maximize the patient's comfort through previous, technical and scientific training; During the handling of the laser, specific items to protect the patient's and professional's eyes from the laser light must be used, as well as all personal protective equipment; and All surgical and operative techniques must be strictly observed.

\section{Authors' Contributions}

\begin{tabular}{|c|c|c|}
\hline KGS & (iD) $0000-0002-9939-6943$ & $\begin{array}{l}\text { Conceptualization, Methodology, Investigation, Formal Analysis, Writing - } \\
\text { Original Draft Preparation and Writing - Review and Editing. }\end{array}$ \\
\hline TYAC & (iD) $0000-0002-1120-6675$ & Conceptualization, Methodology, Investigation and Formal Analysis. \\
\hline AMCS & (iD) $0000-0002-6864-246 \mathrm{X}$ & Conceptualization, Methodology, Investigation and Formal Analysis. \\
\hline LBS & (iD) $0000-0002-2020-9958$ & Formal Analysis and Writing - Original Draft Preparation. \\
\hline $\mathrm{LCMC}$ & (iD) $0000-0002-3843-1186$ & Formal Analysis and Writing - Original Draft Preparation. \\
\hline MLMF & (iD) $0000-0002-5120-1449$ & $\begin{array}{l}\text { Conceptualization, Methodology, Investigation, Formal Analysis and Writing - } \\
\text { Original Draft Preparation. }\end{array}$ \\
\hline $\mathrm{AMF}$ & (iD) $0000-0001-6928-2024$ & Conceptualization, Methodology and Formal Analysis. \\
\hline
\end{tabular}

\section{Financial Support}

None.

\section{Conflict of Interest}

The authors declare no conflicts of interest

\section{References}

[1] Sotoode SM, Azimi S, Taheri SA, Asnaashari M, Khalighi H, Rahmani S, et al. Diode laser in minor oral surgery: a case series of laser removal of different benign exophytic lesions. J Lasers Med Sci 2015; 6(3):133-8. https://doi.org/10.15171/jlms.2015.08

[2] Hsu YP, Chiang ML, Hsu MH. Maxillary frenectomy using diode laser in an infant patient. Taiwan J Oral Maxillofac Surg 2013; 24:126-33.

[3] Desiate A, Cantore S, Tullo D, Profeta G, Grassi FR, Ballini A. 980 nm diode lasers in oral and facial practice: current state of the science and art. Int J Med Sci 2009; 6(6):358-64. https://doi.org/10.7150/ijms.6.358

[4] Akbulut N, Kursun ES, Tumer MK, Kamburoglu K, Gulsen U. Is the 810-nm diode laser the best choice in oral soft tissue therapy? Eur J Dent 2013; 7(2):207-11. https://doi.org/10.4103/1305-7456.110174 
[5] Uraz A, Çetiner FD, Cula S, Guler B, Oztoprak S. Patient perceptions and clinical efficacy of labial frenectomies using diode laser versus conventional techniques. J Stomatol Oral Maxillofac Surg 2018; 119(3):182-86. https://doi.org/10.1016/j.jormas.2018.01.004

[6] Robson, C. Resource for Users of Social Research Methods in Applied Settings. 3rd ed. Chichester: West Sussex; 2011.

[7] Yıldırım A, Şimşek H. Qualitative Research Methods in Social Sciences. 9th ed. Ankara: Seckin Yayincilik; 2014.

[8] Azma E, Safavi N. Diode laser application in soft tissue oral surgery. J Lasers Med Sci 2013; 4(4):206-1 1.

[9] Nicoloso GF, dos Santos IS, Flores JA, da Silveira BL, Oliveira MD. An alternative method to treat ankyloglossia. J Clin Pediatr Dent 2016; 4O(4):319-2 1. https://doi.org/10.17796/1053-4628-40.4.319

[10] Ortega-Concepción D, Cano-Durán JA, Peña-Cardelles JF, Paredes-Rodríguez VM, González-Serrano J, LópezQuiles J. The application of diode laser in the treatment of oral soft tissues lesions. A literature review. J Clin Exp Dent 2017; 9(7):e925-e928. https://doi.org/10.4317/jced.53795

[11] Isola G, Matarese G, Cervino G, Matarese M, Ramaglia L, Cicciù M. Clinical efficacy and patient perceptions of pyogenic granuloma excision using diode laser versus conventional surgical techniques. J Craniofac Surg 2018; 29(8):2 160-3. https://doi.org/10.1097/SCS.0000000000004734

[12] Fornaini C, Rocca JP, Bertrand MF, Merigo E, Nammour S, Vescovi P. Nd:YAG and diode laser in the surgical management of soft tissues related to orthodontic treatment. Photomed Laser Surg 2007; 25(5):381-92. https://doi.org/10.1089/pho.2006.2068

[13] Aras MH, Göregen M, Güngörmüş M, Akgül HM. Comparison of diode laser and Er:YAG lasers in the treatment of ankyloglossia. Photomed Laser Surg 2010; 28(2):173-7. https://doi.org/10.1089/pho.2009.2498

[14] Rahman MS. The Advantages and disadvantages of using qualitative and quantitative approaches and methods in language "testing and assessment" research: a literature review. J Educ Learn 2017; 6(1):102-12. https://doi.org/10.5539/jel.v6n 1p102 